\title{
Coarse-grained description of the spatio-temporal dynamics of network activity from experimentally verified single-neuron models and connectivity
}

\author{
Francesco Fermani", Magnus JE Richardson \\ From 24th Annual Computational Neuroscience Meeting: CNS*2015 \\ Prague, Czech Republic. 18-23 July 2015
}

We combine experimentally constrained models of neocortical neuron voltage dynamics $[1,2]$ and network connectivity [3] to derive a set of equations that describe the activity at a tissue scale. The resulting equations represent a neuronal field theory in which emergent properties at a coarse-grained level can be causally linked to the physiology of cellular and sub-cellular components. The description is mathematically tractable and can be elaborated to include further biophysical details such as multiple neuronal populations to capture the structure of the component microcircuits, synaptic dynamics and filtering as well as distance-dependent delays in signal propagation. For spatially homogeneous afferent drive the steady-state firing rate can be straightforwardly calculated together with the network response to weak spatio-temporal modulation of the afferent drive via a perturbative approach. For the spatially heterogeneous non-linear regime, which the network is pushed into under stronger drive, we construct an iterative numerical scheme that rapidly converges to the network firing rate. The utility of the approach is illustrated using examples from the experimental literature.

Published: 18 December 2015

\section{References}

1. Fourcaud-Trocmé N, Hansel C, van Vresswijk C, Brunel N: How Spike Generation Mechanisms Determine the Neuronal Response to Fluctuating Inputs. J Neurosci 2003, 23(37):11628.

2. Badel L, Lefort $S$, Brette R, Petersen $\mathrm{CCH}$, Gerstner W and Richardson MJE: Dynamic I-V curves are reliable predictors of naturalistic pyramidalneuron voltage traces. J Neurophys 2008, 99(2):656.

*Correspondence: f.fermani@warwick.ac.uk

Warwick Systems Biology Centre, University of Warwick, Coventry, UK
3. Perin R, Berger T K, Markram H: A synaptic organizing principle for cortical neuronal groups. PNAS 2011, 108(13):12.

doi:10.1186/1471-2202-16-S1-P206

Cite this article as: Fermani and Richardson: Coarse-grained description of the spatio-temporal dynamics of network activity from experimentally verified single-neuron models and connectivity. BMC Neuroscience 2015 16(Suppl 1):P206.
Submit your next manuscript to BioMed Central and take full advantage of:

- Convenient online submission

- Thorough peer review

- No space constraints or color figure charges

- Immediate publication on acceptance

- Inclusion in PubMed, CAS, Scopus and Google Scholar

- Research which is freely available for redistribution
( Biomed Central 